\title{
Influence of wood harvest on tree-ring time-series of Picea abies in a temperate forest
}

\author{
Jan Esper ${ }^{\mathrm{a}, *}$, Matthias Benz ${ }^{\mathrm{a}}$, Neil Pederson ${ }^{\mathrm{b}}$ \\ ${ }^{a}$ Department of Geography, Johannes Gutenberg University, Becherweg 21, 55099 Mainz, Germany \\ ${ }^{\mathrm{b}}$ Lamont-Doherty Earth Observatory, 61 Route 9W, Palisades, 10964 NY, USA
}

\section{A R T I C L E I N F O}

\section{Article history:}

Received 17 May 2012

Received in revised form 25 July 2012

Accepted 26 July 2012

\section{Keywords:}

Forest management

Single-tree harvest

Tree-ring width

Dendrochronology

Picea abies

Germany

\begin{abstract}
A B S T R A C T
Tree-ring width data are the prime source of high-resolution climate reconstructions covering recent millennia. Their variations, from year-to-year, are calibrated against regional instrumental data to evaluate the strength of associations with temperature and precipitation records, though the level of variance explained by climatic variables is frequently less than $50 \%$. Among the remaining factors affecting tree growth, the influence of forest management for tree-ring width time-series used to resolve annual climate reconstructions remains relatively unexplored. We here evaluate the impact of conventional single-tree harvesting on tree-ring data using a compilation of circumstantially mapped Picea abies sites in western Germany. Climate signals are explored by calibration against regional temperature and precipitation data, and the influences of forest management analyzed using long-term logging data spanning the past 4080 years and mapped stumps (and neighboring trees) spanning the past 20 years. Our results indicate a weak but statistically significant control of total May-July precipitation of $P$. abies growth. This association is only marginally, if at all, affected by forest management, i.e. wider tree-rings due to improved access to light and nutrients in years after logging events are either not found or in line with increased precipitation sums following single-tree harvest. These findings suggest only minor influences of selective harvesting on Picea tree-ring growth in western Germany, and overall limited biases of annually resolved climate reconstructions from lower elevation central European sites due to historical logging events.
\end{abstract}

(c) 2012 Elsevier B.V. All rights reserved.

\section{Introduction}

High-resolution temperature and precipitation reconstructions spanning the past several hundred to thousand years are of importance to evaluate the role of natural, pre-industrial forcing of climate and considered in simulations of future changes using coupled climate models (IPCC, 2007). Most of these records highlight longer-term temperature variations based on tree-ring width (TRW) data from cold ecotone sites, but reconstruction of precipitation variability, mainly based on TRW from lower elevation sites, has also been identified valuable when addressing global climate change (Cook et al., 2004, 2010; Frank et al., 2010). Büntgen et al. (2011) have recently reconstructed precipitation variations over the past 2500 years in central Europe using large TRW datasets from low elevation sites in southwestern Germany and northeastern France. These results indicate considerable, preinstrumental precipitation deviations in line with major cultural changes throughout the Common Era.

Whereas the climate signals in TRW and associated density time-series are typically evaluated in great detail (e.g., Esper

\footnotetext{
* Corresponding author. Tel.: +49 6131 3922296; fax: +49 61313924735.

E-mail address: esper@uni-mainz.de (J. Esper).
}

et al., 2010), the influence of forest management and particularly of single-tree harvest on these signals is not well investigated in an European context (Bräker and Baumann, 2006; Epp, 2004; Schweingruber, 1996; though see work from Asia and the Americas: Pollmann, 2002; Orwig and Abrams, 1999; Song et al., 2011). This limited attention to potentially biasing factors inherent to dendroclimatological reconstructions is somewhat surprising, as (i) the positive effects of selective harvesting on wood productivity through reduced plant competition for light and increased access to nutrients is well-documented in forestry literature (e.g., Kramer, 1988 and references therein; Rentch et al., 2002) and (ii) these disturbance signals can impact the tree-ring/climate calibrations trials that are typically used to assign temperature or precipitation scales to historical wood collections spanning the past several hundred to thousand years (Cook and Kairiukstis, 1990; Fritts, 1976). We here address this question by developing a larger dataset composed of three circumstantially mapped lower elevation Picea abies sites in western Germany, and analyzing the climatic signals and effects of conventional single-tree harvest over recent decades. We (i) selected forest sites from which long-term logging data are available, (ii) sampled all trees (dominant, subdominant, and suppressed) within predefined, homogeneous plots, (iii) dated felling events over the past 20 years using core samples obtained from preserved stumps, and (iv) assessed the growth response to felling 
events and climate signals in remaining trees in various distance classes to the stumps. We focused on P. abies in this study as it represents the most widespread species in German forests ( $28 \%$ of area), is of significant value to forest productivity, and has intensively been managed throughout the 20th century.

We hypothesize that wood harvest in these sites is entailing substantially wider rings in the years following logging events, and that these disturbance signals result in a temporal decoupling of the TRW time-series from otherwise controlling precipitation variations. The objectives include (i) an evaluation of precipitation and temperature signals retained in the mean chronologies of three $P$. abies sites in western Germany, (ii) an assessment of the influence of logging on the site chronologies through comparison with wood harvest data spanning the past $40-80$ years, and (iii) an estimation of the effects of single-tree harvest through the analysis of growth responses of the remaining trees (surrounding the dated stumps) over the past 20 years.

\section{Materials and methods}

\subsection{Sampling sites and wood harvest data}

Fifty $P$. abies trees were sampled (two cores per tree) in three ecologically homogeneous plots in $440-460 \mathrm{~m}$ a.s.l. in the Rheinische Schiefergebirge using $5 \mathrm{~mm}$ increment borers. One of the sites (Zel) is located in the Hunsrück region between the rivers Mosel and Nahe, two others (Wam and Wun) in the Taunus region between the rivers Lahn and Main (Fig. 1). Climatic conditions in these sites are characterized by seasonal temperature variations in the order of $17^{\circ} \mathrm{C}$ (max. temperatures in July) and relatively balanced precipitation sums throughout the year. The Wam and Wun sites likely receive less rainfall (relative to Zel) as revealed by the nearby stations Geisenheim ( $549 \mathrm{~mm}$ year $^{-1}$ ) relative to Blankenrath $\left(856 \mathrm{~mm}_{\text {year }}{ }^{-1}\right)$, though the Geisenheim station is located in lower elevations leeward to the rain-laden westerlies.
When sampling each site, we measured the distance between all trees $>15 \mathrm{~cm}$ diameter breast height $(\mathrm{DBH})$ using a laser and considering the azimuth from a reference direction within each site (Fig. 2). Stumps were dated if decomposition status allowed obtaining core samples. This strategy enabled the use of 10 out of 37 stumps in Wam, 5 out of 23 stumps in Wun, and 12 out of 45 stumps in Zel (Table 1) for superposed epoch analysis (SEA, see below). Mean and maximum tree ages are highest in Wam (123 and 154 years) followed by Wun (82 and 141 years), and Zel (48 and 57 years), and interseries correlations (Rbar, Fritts, 1976) $>0.63$ in all sites substantiate successful dating and common forcing of TRW variations.

Long-term wood harvesting data including the year of logging and the harvested bank meters (BM, volume of solid wood in cubic meter) were available back to 1949 in Wam, 1932 in Wun, and 1974 in Zel. The BM data, provided by the local foresters and representing different large areas (the German 'Abteilung'), were transferred into numbers of logged trees considering the average tree and diameter breast heights recorded in each sampling site (see equations in Mitscherlich, 1970; Pretzsch, 2001) (Fig. 3). These data enabled a straightforward assessment of logging and TRW data, and comparison among sampling sites. In addition, we considered the exact positions of dated stumps to evaluate growth responses of (remaining) trees in distance classes $<5 \mathrm{~m},>5 \mathrm{~m}$, $5-10 \mathrm{~m}$, and $>10 \mathrm{~m}$ relative to the stumps to estimate the effects of single-tree logging within each site. Logging practice typically includes removal of single dominant trees to improve access to nutrients and light of remaining plants.

\subsection{Tree-ring detrending, calibration, and superposed epoch analysis (SEA)}

Both raw and detrended TRW data were used to assess the influence of wood harvest on dendrochronological time-series. For detrending, age-related trends in the raw TRW measurement

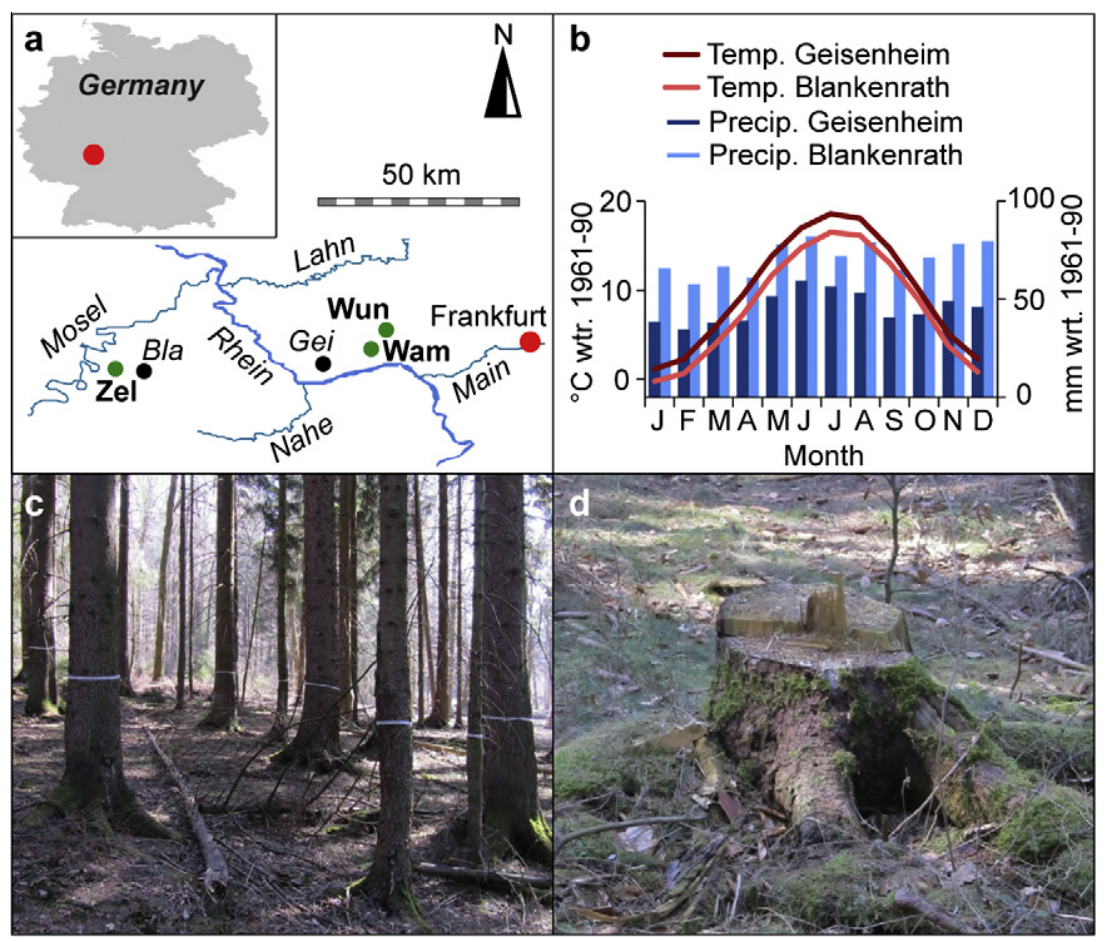

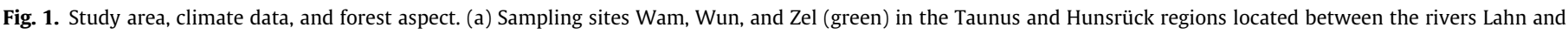

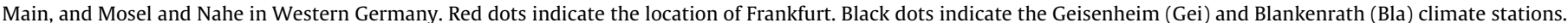

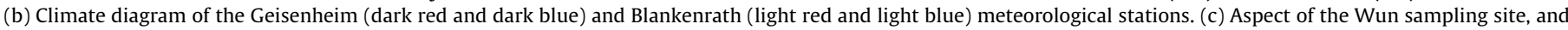
(d) stump of a spruce tree harvested in 2006. (For interpretation of the references to color in this figure legend, the reader is referred to the web version of this article.) 

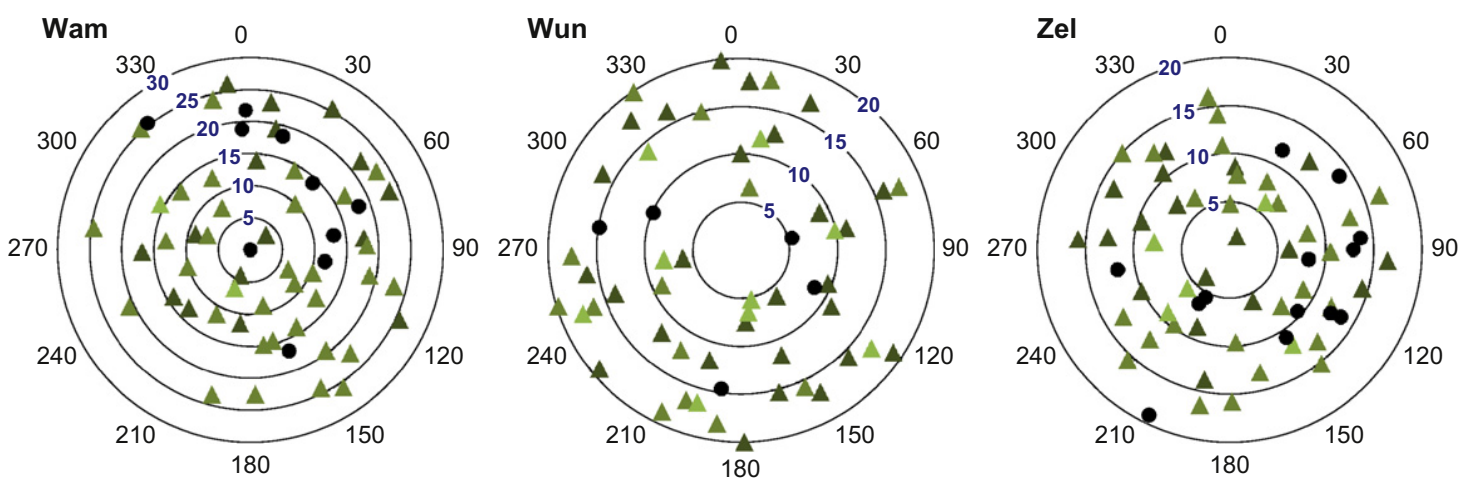

$\boldsymbol{\Delta}$ Dominant $\Delta$ Subdominant $\Delta$ Suppressed

Stump

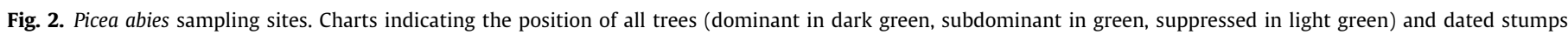

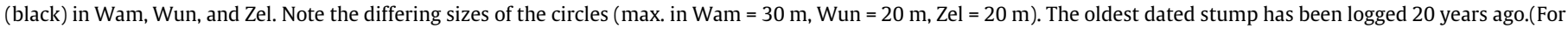
interpretation of the references to color in this figure legend, the reader is referred to the web version of this article.)

Table 1

Sampling site characteristics.

\begin{tabular}{|c|c|c|c|c|c|c|c|c|}
\hline Site & Eleva-tion (m) & Size $\left(\mathrm{m}^{2}\right)$ & No. of trees (cores) & Dom./sub-dom./supp. ${ }^{a}$ & Max. age & Mean age & Rbar $^{\mathrm{b}}$ & No. of dated/all stumps \\
\hline Wam & 450 & 2256 & $50(99)$ & $16 / 32 / 2$ & 154 & 123 & 0.63 & $10 / 37$ \\
\hline Wun & 460 & 1256 & $41(82)$ & $23 / 14 / 4$ & 141 & 82 & 0.63 & $5 / 23$ \\
\hline Zel & 440 & 1146 & $49(96)$ & $18 / 27 / 4$ & 57 & 48 & 0.77 & $13 / 45$ \\
\hline
\end{tabular}

a Dominant/subdominant/suppressed.

b Interseries correlation calculated among 30-year spline detrended time-series.

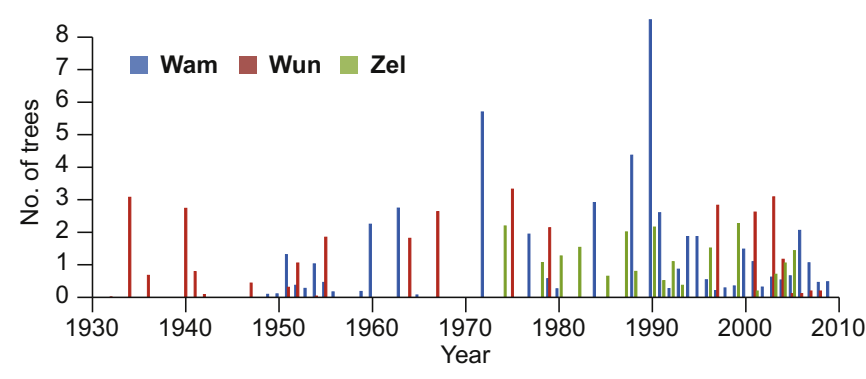

Fig. 3. Long-term wood harvest data. BM data have been transformed into numbers of trees for each site (see text), reaching back to 1949 in Wam, 1932 in Wun, and 1974 in Zel.

series were removed using the Regional Curve Standardization technique (RCS; Esper et al., 2003). This approach included (i) a power transformation of the original data to remove variance changes associated with tree age (Cook and Peters, 1997), (ii) alignment of the transformed series by biological age, considering the number of missing innermost rings on some core samples (the so-called pith-offset; Esper et al., 2009), (iii) smoothing the mean of the age-aligned data using a spline function (Cook and Peters, 1981), and (iv) calculation of residuals between the measurement series and the smoothed mean value function. The detrended TRW time-series were then dated back to calendar years, and averaged for each tree (two cores per tree), site, and distance class for subsequent analyses. RCS removes the underlying age-trend common to all TRW series in a site, and does not impact higher frequency, inter-annual to inter-decadal scale variations typical for management-induced disturbance signals (Briffa et al., 1992; Esper et al., 2003).

Mean TRW site chronologies were calibrated against monthly (and May-July seasonal) precipitation and temperature data recorded at the nearby Geisenheim and Blankenrath stations (Fig. 1) back to 1885 and 1947, respectively, to estimate the common climatic control of $P$. abies growth. We also calculated Pearson correlation coefficients using gridded Palmer Drought Severity Index data after Dai et al. (2004) and Van der Schier et al. (2006), but consideration of these parameters didn't improve the calibration results (not shown).

To evaluate the effect of wood harvest on TRW data and association with climate data, SEA (Panofsky and Brier, 1958) has been applied considering the felling events derived from long-term logging data as well as the dated stumps along with the detrended TRW and May-July precipitation time-series. In detail, we aligned the precipitation and TRW data with respect to logging events $>1$ tree, $>2$ trees, and $>3$ trees over the past $40-80$ years (=year 0 in SEA), and analyzed TRW and precipitation deviations five years before and after the events. Similarly, precipitation and TRW data were aligned with respect to the felling dates of the stumps. However, in this second approach the TRW data were not averaged for each site but the distance classes, $<5 \mathrm{~m}$ from a stump, .., $>10 \mathrm{~m}$. Cross-comparison of TRW, precipitation, and logging data through SEA allows a first-order differentiation of the significance of wood harvest versus climate influences on tree growth.

\section{Results}

\subsection{Climate signals}

Correlation patterns between TRW chronologies and regional temperature and precipitation data are similar among the three sampling sites, though monthly coefficients barely exceed 0.4 (Fig. 4). TRW time-series are generally positively correlated with late spring and summer rainfall, and inversely (and less strongly) with summer temperatures (except August). Strongest coherence is revealed with May-July precipitation sums, in line with expectations based on network analyses from Germany and Europe integrating multiple tree species (Babst et al., in press; Neuwirth et al., 2007). The May-July precipitation signal remains reasonably stable over time, though there is some indication of an increased 


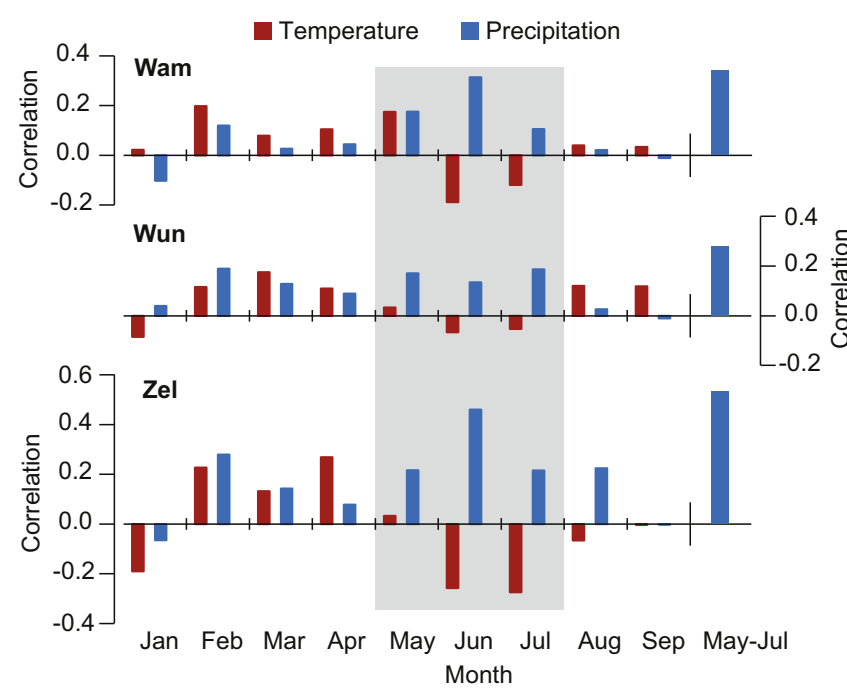

Fig. 4. Seasonal climate signals. Pearson correlations among detrended TRW timeseries and monthly (January-September) temperature and precipitation data over the 1885-2010 (Wam and Wun) and 1954-2010 (Zel) common periods. Right column shows the results for May-July precipitation sums. May-July signals are statistically significant at $p<0.001$ in Wam and Zel, and $p<0.01$ in Wun.
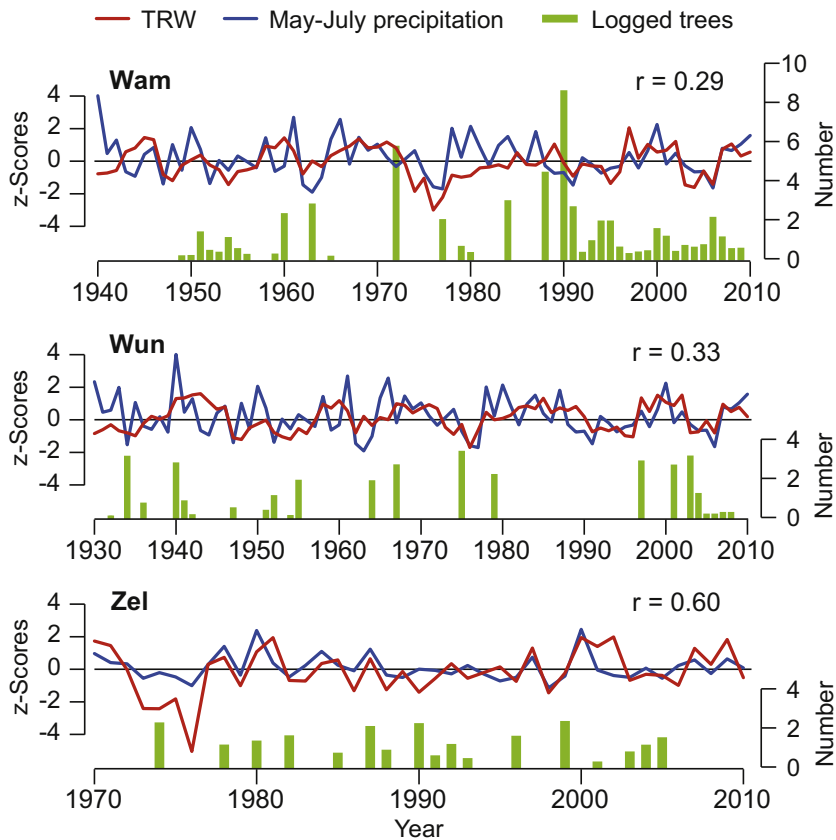

Fig. 5. Tree-ring, precipitation and logging data. Detrended TRW chronologies shown together with regional May-July precipitation time-series and long-term wood harvest data back to 1940 (Wam), 1930 (Wun), and 1970 (Zel). TRW and precipitation time-series were normalized, and wood harvest data transferred into numbers of trees. Correlations between TRW and precipitation refer to displayed periods over which long-term wood harvest data are available.

coherence with rainfall totals at the beginning of the 20th century and towards present (Supplementary Data). These results underline the demand for a balanced water supply throughout the summer season typical for $P$. abies in central European low elevation sites.

The importance of May-July precipitation for $P$. abies tree-ring growth is reinforced by the time-series displayed over varying periods of time over which long-term logging data are available in Wam, Wun, and Zel (Fig. 5). The course of TRW and precipitation variations suggests an even stronger association at decadal timescales in Wam and Wun. Lower frequency variations, beyond
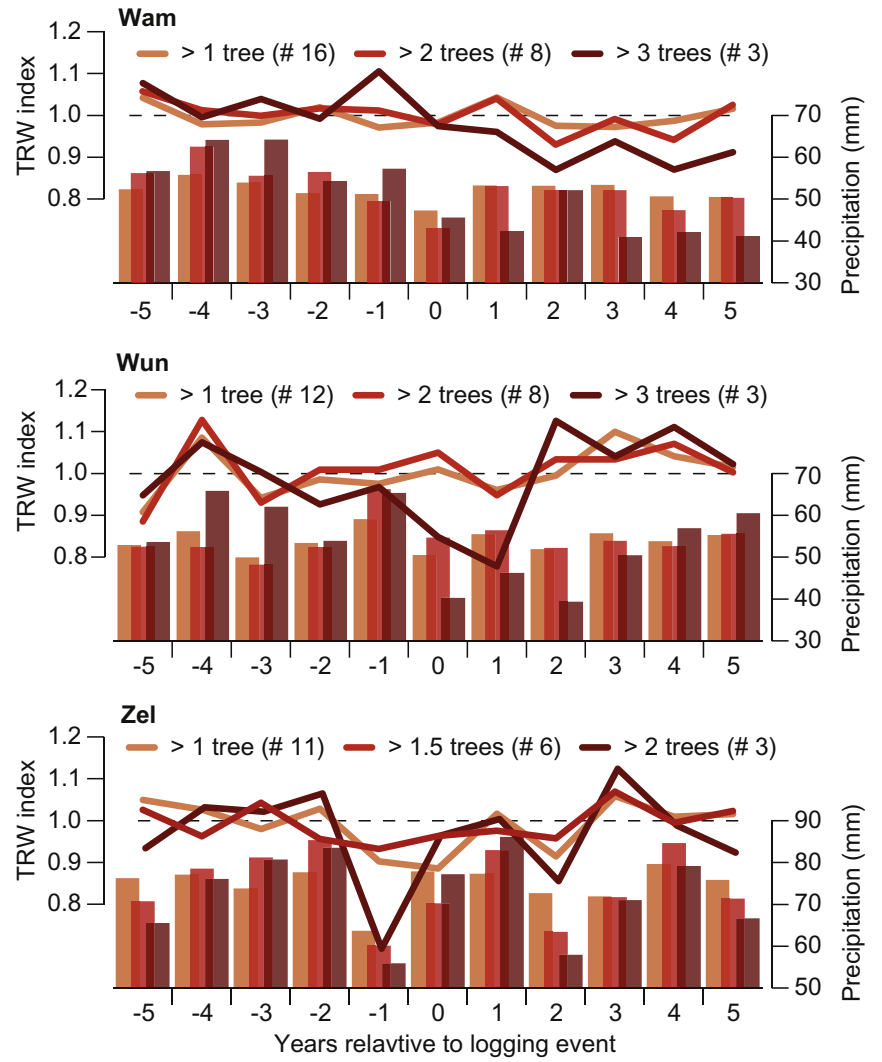

Fig. 6. SEA analysis centered on logging events (year 0 ) derived from long-term wood harvest data. Curves represent detrended TRW time-series centered on logging events $>1$ tree (light red), $>2$ trees (red; $>1.5$ trees in Zel), and $>3$ trees (dark red; $>2$ trees in Zel) derived from long-term wood harvest data (see Fig. 5). Values in parentheses refer to numbers of years in which these thresholds were exceeded. Histograms at the bottom of the panels summarize the May-July precipitation data centered on the logging event years. (For interpretation of the references to color in this figure legend, the reader is referred to the web version of this article.)

inter-annual timescales, are reduced in Zel, though the period covered by instrumental (and long-term logging) data is substantially shorter in this site. Comparison with long-term logging data (shown in green ${ }^{1}$ in Fig. 5) suggests no obvious relationship between wood harvest and TRW data in the form of post-logging growth releases, but this association is more thoroughly investigated using SEA (see Sections 3.2 and 3.3 below). Whereas the logging data in Wun and Zel are evenly distributed throughout time, wood harvest has been less intensive but more regular in the 1950s and after 1990 in Wam.

\subsection{Coherence with long-term logging data}

Temporal alignment of the felling events using SEA revealed no clear effect of forest management on $P$. abies TRW throughout the past 40-80 years (Fig. 6). TRW time-series either decline (Wam) or indicate no obvious change (Wun and Zel) in years following felling activities. This conclusion appears to be independent of the intensity of logging events (see the different curves in Fig. 6 representing varying thresholds of logging intensity), with only the grouped events $>3$ trees in Wun showing a substantial growth release two years after wood harvest. The latter case is, however, only weakly replicated (\#3), which is also reflected in the increased variance in TRW and precipitation time-series when fewer events are integrated in the SEA.

\footnotetext{
${ }^{1}$ For interpretation of color in Fig. 5, the reader is referred to the web version of this article.
} 
The SEA patterns also validate the coupling between TRW and May-July precipitation as revealed by the correlation results presented in Section 3.1. This association seems largely unaffected by felling activities, perhaps except for the high-impact logging events $>3$ trees in Wun, where precipitation is reduced but TRW increased in post-logging years (except year +1 ). Coherence with precipitation data is not very strong (and diverse among sampling sites and logging classes) again reinforcing the overall weak climate control of $P$. abies growth in western German low elevation environments.

\subsection{Effects of recent logging on neighboring trees}

When directing the SEA on trees surrounding dated stumps in various distance classes, wider tree-rings in post-logging years
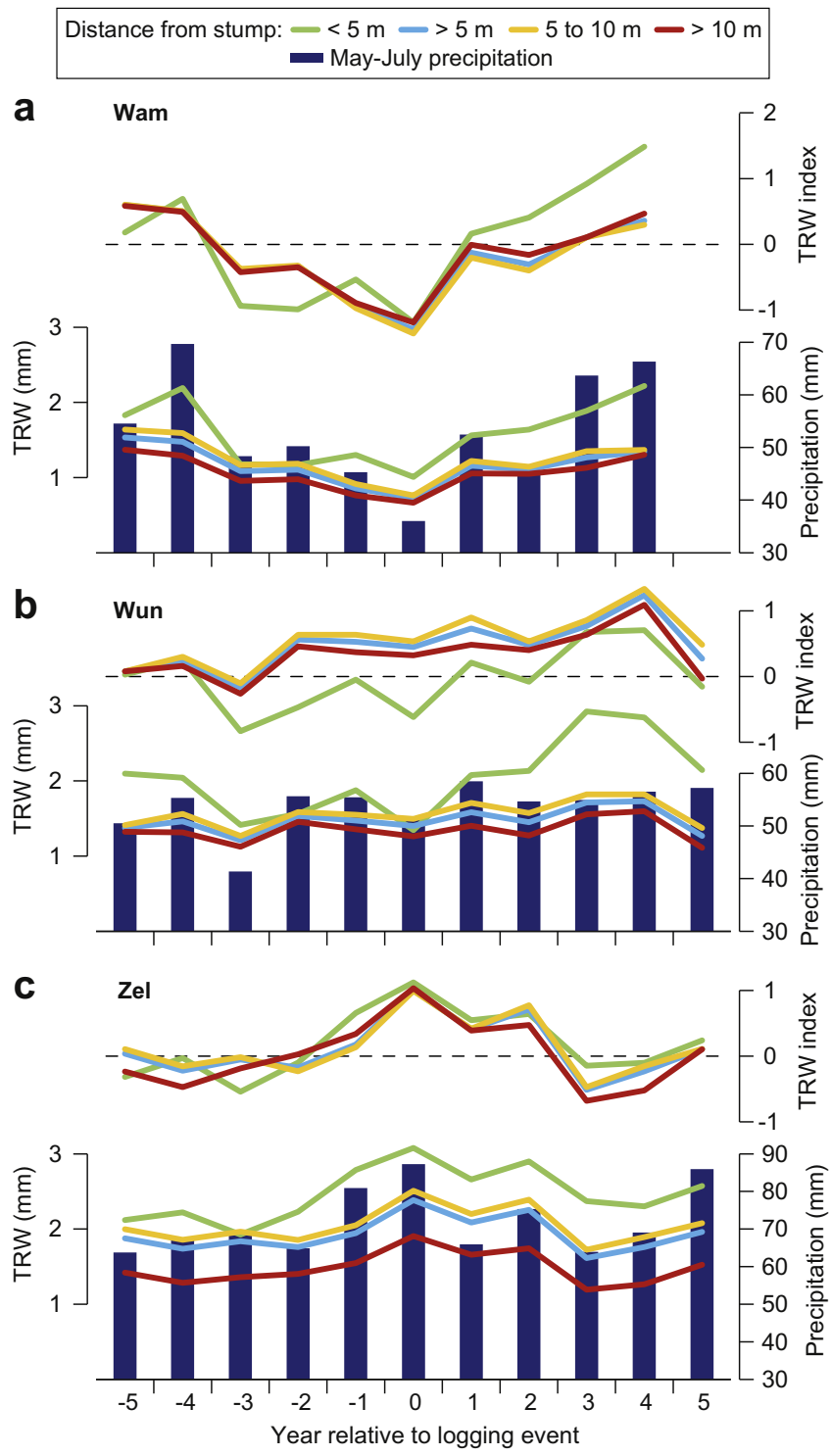

Fig. 7. SEA based on dated stumps over the past two decades. Curves represent detrended (top of the panels) and raw (middle of the panels, in mm) TRW timeseries centered on logging events (year 0 ), i.e. the felling dates of the stumps shown in Fig. 2. Green curves show the mean TRW series of trees in $<5 \mathrm{~m}$ distance to the stumps, blue curves in $>5 \mathrm{~m}$, yellow curves in 5-10 $\mathrm{m}$, and red curves in $>10 \mathrm{~m}$. The numbers of TRW series averaged in these curves range from 5 (distance class $>10 \mathrm{~m}$ in Zel) to 39 (distance class $>5 \mathrm{~m}$ in Wam) with an average replication of 20 trees. Histograms at the bottom of the panels summarize the May-July precipitation data centered on the logging event years. (For interpretation of the references to color in this figure legend, the reader is referred to the web version of this article.) are revealed in Wam and Wun, but no effect is seen in Zel (Fig. 7). This, in part diverse response, is contrasting with a homogeneous precipitation signal recorded in all sites, i.e. the aligned TRW and May-July precipitation time-series match closely in years before and after logging events. In Wam and Wun, post-logging growth releases are emphasized in the smallest distance class $<5 \mathrm{~m}$ (the green curves in Fig 7), with the effect being more obvious in the non-detrended TRW time-series (in mm). In Zel, all four distance classes showed synchronous patterns, though a level offset is recorded in the raw measurement series.

Importantly, the course of the SEA centered TRW time-series closely matches the centered precipitation data (the histograms in Fig. 7), indicating that the P. abies climate signal remains undisturbed from logging activities over the past 20 years. This conclusion holds particularly for Zel, where no growth release is recorded, and for Wam, where deviating $<5 \mathrm{~m}$ TRW values are in line with increasing precipitation sums in post-logging years. This association seems to be disturbed in Wun only, where the trees closest to the stumps indicate substantially wider rings 2-5 years after wood harvest, a pattern that is conflicting with the more distant trees and not supported by post-logging precipitation totals.

\section{Discussion and conclusions}

P. abies is a key species in central European forestry. Due to its wide ecological range and rapid growth, it has been cultivated over centuries and became a dominant species in temperate forests even in areas where local site and climate conditions would naturally support other species. P. abies is undemanding with respect to nutrient supply and grows in dense forests where competition for sunlight is a basic limiting factor of stem wood productivity. These characteristics together with its extensive use in tree-ring based climate reconstructions make it a suitable species for studying effects of wood harvest on TRW time-series.

Doing so, however, requires access to detailed wood harvest data as well as precise mapping of single trees and stumps within forest sites (Bräker and Baumann, 2006). We completed these tasks for three temperate sites from which more than 300 tree and stump core samples were collected and TRW measured. Linking these data with long-term harvest histories, that represent typical forest management practices for the region, allowed an estimation of the significance of single-tree logging on P. abies stem growth and climate signals. While these analyses are still limited with respect to plant competition effects, due to the unspecified positions of felled trees in the BM data, the assessment of accurately mapped trees surrounding dated stumps as carried out here using SEA, enabled a thorough estimation of post-logging growth releases and potential biases on TRW climate signals with respect to stump distance.

Our results indicate climate signals ranging from $~ 15 \%$ to $35 \%$ of instrumental May-July precipitation explained in low elevation spruce tree-ring data. This weak but significant association remained largely unaffected by logging activities, which appeared somewhat surprising as the positive effects of wood harvest on tree growth are widely documented in European forestry literature (Assmann, 1970; Kramer, 1988; Pretzsch, 2001; Spiecker, 1996). This conclusion is, however, constrained by the setup of our analysis and the inaccuracy of the long-term harvest data that have been transferred into numbers of trees per sampling site. Consideration of circumstantially mapped trees and precisely dated stumps overcomes some of these uncertainties, suggesting disturbance signals to be effective in the immediate vicinity of the stumps (distance class $<5 \mathrm{~m}$, in two out of three sites).

The overall limited impact of logging on the radial growth of surviving trees seen here conflicts with evidence that a change in 
competitive pressure impacts TRW (e.g., Lorimer, 1980; Nowacki and Abrams, 1997; Rentch et al., 2002). As early as the1920s it was observed that abrupt and sustained increases in TRW seemed to occur simultaneously with evidence of logging (Marshall, 1927). Growth releases were even found to occur as a result of a reduction in tree-to-tree competition in low-density forests (Bhuta et al., 2008; Meldahl et al., 1999; Pederson et al., 2008). However, work on Quercus revealed only minor post-logging responses if crowns were exposed by less than $15 \%$ ( $\sim 30 \%$ of basal area for mature trees) through logging (reviewed in Nowacki and Abrams, 1997) or low intensity harvesting from below (Rentch et al., 2002).

We here showed that growth pulses following felling events do, however, not necessarily disturb the climate signal retained in TRW data. This conclusion is supported by synchronous TRW and precipitation variations in post-logging years in two of the three sampled sites, and is in line with evidence from randomly-selected trees in cut forests and even anthropogenically-created, low density stands (Pederson et al., in press). The significance of undisturbed climate signals could potentially be further clarified through sampling and mapping more sites, and dating stumps beyond the past two decades. The latter strategy seems to be limited with $P$. abies in temperate environments, as rapid wood decay hinders collecting older stumps that can precisely be dated to the calendar year. More resistant species (e.g., larch) from colder environments, where wood decay is decelerated (Büntgen et al., 2006), might be an alternative to study the effects of wood harvest on tree growth and climate signals.

Another source of uncertainty is related to the quality of the long-term logging data. While we have been assured by the local foresters that logging practice did not change over the past 40 80 years in the multiple sites, it seems likely that todays single-tree harvest techniques differ from the techniques applied during the mid 20th century, at least with respect to the size and impact of the machines used to remove felled stems. The long-term logging data are also recorded over areas ('Abteilungen') that are larger than the sites mapped and sampled within this study. Consequently, the logging events derived from these data contain some uncertainty that might increase towards the smaller scale (e.g., $<2$ and $<1$ tree) events. An alternative would be to sample a whole Abteilung, but this would mean collecting and analyzing hundreds of cores, and it seems more appealing to work with several sites rather than one mega site.

The results presented here suggest only minor biases inherent to TRW based central European precipitation reconstructions (e.g., Büntgen et al., 2011) due to typical single-tree harvest. More studies considering long-term harvest data, perhaps even from higher elevation environments to assess impacts on annually resolved temperature reconstructions (Büntgen et al., 2008; Esper, 2000; Esper et al., 2007), are needed to further evaluate potential influences of plant competition and nutrient access in the proximity of felled trees. Integrative analyses using a standardized sampling scheme (including mapping of sites and dating of stumps) applied in various climate zones and considering several species would help to further understanding of the noise retained in long-term tree-ring records. Combination of such studies with analyses of changing historical forestry practices appear particularly important in an European context, where wood harvest has been significant over recent millennia (Kaplan et al., 2009).

\section{Acknowledgements}

We thank Cornelia Berger, Klaus Stolpp, and Marcel Stumpf for permission and support to sample Picea abies sites in the Hunsrück and Taunus. Supported by the Mainz Geocycles Research Centre.

\section{Appendix A. Supplementary material}

Supplementary data associated with this article can be found, in the online version, at http://dx.doi.org/10.1016/j.foreco.2012.07.047.

\section{References}

Assmann, E., 1970. The Principles of Forest Yield Study: Studies in the Organic Production, Structure, Increment, and Yield of Forest Stands. Pergamon, London.

Babst, F., Poulter, B., Trouet, V., Kun, T., Neuwirth, B., et al., in press. Site-and speciesspecific response of forest growth to climate across the European continent. Glob. Ecol. Biogeogr.

Bhuta, A.R., Kennedy, L.M., Copenheaver, C.A., Sheridan, P.M., Campbell, J.B., 2008. Boundary-line growth patterns to determine disturbance history of remnant longleaf pine (Pinus palustris P. Mill) in mixed forests of southeastern Virginia. J. Torrey Bot. Soc. 135, 516-529.

Bräker, O.U., Baumann, E., 2006. Growth reactions of sub-alpine norway spruce (Picea abies (L.) Karst.) following one-sided light exposure (case study at Davos "Lusiwald"). Tree-Ring Res. 62, 67-73.

Briffa, K.R., Jones, P.D., Bartholin, T.S., Eckstein, D., Schweingruber, F.H., Karlen, W., Zetterberg, P., Eronen, M., 1992. Fennoscandian summers from AD 500: temperature changes on short and long timescales. Clim. Dyn. 7, 111-119.

Büntgen, U., Esper, J., Bellwald, I., Kalbermatten, H., Schmidhalter, M., Freund, H., Bellwald, W., Neuwirth, B., 2006. 700 years of settlement and building history in the Lötschental/Valais. Erdkunde 60, 96-112.

Büntgen, U., Frank, D., Grudd, H., Esper, J., 2008. Long-term summer temperature variations in the Pyrenees. Clim. Dyn. 31, 615-631.

Büntgen, U., Tegel, W., Nicolussi, K., McCormick, M., Frank, D., Trouet, V., Kaplan, J.O., Herzig, F., Heussner, K.-U., Wanner, H., Luterbacher, J., Esper, J., 2011. European climate variability and human susceptibility over the past 2500 years. Science 331, 578-582.

Cook, E.R., Kairiukstis, L.A. (Eds.), 1990. Methods of Dendrochronology: Applications in Environmental Science. Kluwer Academic Publishers, Dordrecht.

Cook, E.R., Peters, K., 1981. The smoothing spline: a new approach to standardizing forest interior tree-ring width series for dendroclimatic studies. Tree-Ring Bull. 41, 45-53.

Cook, E.R., Peters, K., 1997. Calculating unbiased tree-ring indices for the study of climatic and environmental change. Holocene 7, 361-370.

Cook, E.R., Woodhouse, C.A., Eakin, M., Meko, D.M., Stahle, D.W., 2004. Long-term aridity changes in the Western United States. Science 306, 1015-1018.

Cook, E.R., Anschukaitis, K.J., Buckley, B.M., D’Arrigo, R.D., Jacoby, G.C., Wright, E.W., 2010. Asian monsoon failure and mega drought during the last millennium. Science 328, 486-489.

Dai, A., Trenberth, K.E., Qian, T., 2004. A global data set of palmer drought severity index for 1870-2002: relationship with soil moisture and effects of surface warming. J. Hydrometeor. 5, 1117-1130.

Epp, P., 2004. Zur Abschätzung des Zuwachspotentials von Fichten und Tannen nach starker Freistellung in Plenterüberführungsbeständen. Freiburger Forstl. Forsch. 24, Freiburg.

Esper, J., 2000. Long-term tree-ring variations in juniperus at the upper timberline in the Karakorum (Pakistan). Holocene 10, 253-260.

Esper, J., Cook, E.R., Krusic, P.J., Peters, K., Schweingruber, F.H., 2003. Tests of the RCS method for preserving low-frequency variability in long tree-ring chronologies. Tree-Ring Res. 59, 81-98.

Esper, J., Frank, D.C., Wilson, R.J.S., Büntgen, U., Treydte, K., 2007. Uniform growth trends among central Asian low and high elevation juniper tree sites. Trees 21, $141-150$.

Esper, J., Frank, D., Büntgen, U., Kirdyanov, A., 2009. Influence of pith offset on treering chronology trend. Trace 7, 205-210.

Esper, J., Frank, D.C., Büntgen, U., Verstege, A., Hantemirov, R.M., Kirdyanov, A.V., 2010. Trends and uncertainties in Siberian indicators of 20th century warming. Glob. Change Biol. 16, 386-398.

Frank, D., Esper, J., Zorita, E., Wilson, R.J.S., 2010. A noodle, hockey stick, and spaghetti plate: a perspective on high-resolution paleoclimatology. Wiley Interdiscipl. Rev. Clim. Change 1, 507-516.

Fritts, H.C., 1976. Tree Rings and Climate. Academic Press, London.

IPCC, 2007. Climate Change 2007: The Physical Science Basis. Cambridge Univ. Press, Cambridge.

Kaplan, J.O., Krumhardt, K.M., Zimmermann, N., 2009. The prehistorical and preindustrial deforestation of Europe. Quat. Sc. Rev. 28, 3016-3034.

Kramer, H., 1988. Waldwachstumslehre. Parey, Hamburg.

Lorimer, C.G., 1980. Age structure and disturbance history of a southern Appalachian virgin forest. Ecology 61, 1169-1184.

Marshall, R., 1927. The growth of hemlock before and after release from suppression. Harvard For. Bull. 11, 1-43.

Meldahl, R.S., Pederson, N., Kush, J.S., Varner, J.M., 1999. Dendrochronological investigations of climate and competitive effects on longleaf pine growth. In: Wimmer, R., Vetter, R.E. (Eds.), Tree Ring Analysis: Biological, Methodological and Environmental Aspects. CAB International, Wallingford, pp. 265-285.

Mitscherlich, G., 1970. Wald, Wachstum und Umwelt. Form und Wachstum von Baum und Bestand. Sauerländer, Frankfurt.

Neuwirth, B., Schweingruber, F.H., Winiger, M., 2007. Spatial patterns of Central European pointer years from 1901 to 1971 . Dendrochronologia 24, 79-89. 
Nowacki, G.J., Abrams, M.D., 1997. Radial-growth averaging criteria for reconstructing disturbance histories from presettlement-origin oaks. Ecol. Monogr. 67, 225-234.

Orwig, D.A., Abrams, M.D., 1999. Impacts of early selective logging on the dendroecology of an old growth, bottomland hemlock-white pine-northern hardwood forest on the Allegheny Plateau. J. Torrey Botan. Soc. 126, 234-244.

Panofsky, H.A., Brier, G.W., 1958. Some Applications of Statistics to Meteorology. Univ Park, Pennsylvania.

Pederson, N., Varner III, J.M., Palik, B.J., 2008. Canopy disturbance and tree recruitment over two centuries in a managed longleaf pine landscape. For. Ecol. Manage. 254, 85-95.

Pederson, N., Tackett, K., McEwan, R.W., Clark, S., Cooper, A.M., Brosi, G., Eaton, R. Stockwell, R.D., in press. Prospects for reconstructing drought using nonclassical tree-ring data: drought as an important factor of tree growth. Can. J. For. Res.
Pollmann, W., 2002. Effects of natural disturbance and selective logging on nothofagus forests in south-central Chile. J. Biogeogr. 29, 955-970.

Pretzsch, H., 2001. Grundlagen der Waldwachstumsforschung. Blackwell, Berlin. Rentch, J.S., Desta, F., Miller, G.W., 2002. Climate, canopy disturbance, and radial growth averaging in a second-growth mixed-oak forest in West Virginia, USA. Can. J. For. Res. 32, 915-927.

Schweingruber, F.H., 1996. Tree Rings and Environment - Dendroecology. Haupt, Bern.

Song, K., Yu, Q., Shang, K., Yang, T., Da, L., 2011. The spatio-temporal pattern of historical disturbances of an evergreen broadleaved forest in East China: a dendroecologicla analysis. Plant Ecol. 212, 1313-1325.

Spiecker, H., 1996. Growth Trends in European Forests: Studies from 12 Countries. Springer, Berlin.

Van der Schrier, G., Briffa, K.R., Jones, P.D., Osborn, T.J., 2006. Summer moisture variability across Europe. J. Clim. 19, 2818-2834. 